\title{
FACILITATING CLASS DISCUSSIONS AROUND CURRENT AND CONTROVERSIAL ISSUES TEN RECOMMENDATIONS FOR TEACHERS
}

\author{
Souha R. Ezzedeen
}

\section{Abstract. Facilitating productive class discussions is one of the most challenging tasks facing college educators, especially when potentially divisive issues are discussed. The author shares ten recommendations derived from teaching a course on current and contro- versial managerial issues via conversational learning. Excerpts from student comments are included to dem- onstrate the appropriateness of these recommenda- tions. These recommendations are applicable to con- versations across subjects and are meant to encourage college teachers to experiment with conversational learning in their own classrooms.}

\section{Meywords: controversial issues, conversational learning, discussion}

eading productive class discussions, Lones that challenge students intellectually and engage them affectively, is probably one of the most complex and difficult tasks facing college educators. Although much is known about discussion as a way of teaching (e.g., Baker, Jensen, and Kolb 2002a; Brookfield and

Souha R. Ezzedeen is an assistant professor of human resources management at York University's School of Administrative Studies. Her research interests include conversational learning pedagogies, work and life issues, and women's advancement.
Preskill 1999), far fewer writings address how teachers can facilitate conversational learning-that is, "the process whereby learners construct meaning and transform experiences into knowledge through conversations" (Kolb, Baker, and Jensen 2002, 51)—especially when current issues of a controversial nature are discussed. Conversations essentially refer to

a broad set of conversational activities in which a group of two or more people consider a subject, and as well, all discussion participants are encouraged to interact with each other by speaking, by using nonverbal cues, and by listening to enrich and refine understanding. (Billings and Fitzgerald 2002, 907-8)

Although "discussion," "dialogue," and "conversation" have been used interchangeably, some researchers have drawn distinctions between these terms, understanding "conversation" as a generally informal and cooperative effort, "dialogue" as a concerted problem-solving endeavor, and "discussion" as concerned with knowledge development, similar to Baker, Jensen, and Kolb's (2002b) conceptualization of conversational learning as "individuals coming together in a joint meaning-making process" (4; see Brookfield and Preskill 1999 and Innes 2007 for a fuller account of the differences between discussion, dialogue, and conversation).

My goal in this article is to share with educators recommendations derived from teaching a course that was entirely structured around discussion of current and controversial social, cultural, and political issues facing the business community today. The focus on such problems stemmed from evidence that business students generally tend to lack a thorough understanding of and sympathy toward such contemporary issues as work-life balance, the erosion of job security, and environmental degradation (Rynes and Trank 1999). Furthermore, the course's emphasis on discussion as the key pedagogy ultimately aimed at developing cognitive and behavioral competencies among students toward 
these problems (Rossouw 2002). Cognitive competencies allow individuals to "identify, analyze, judge and evaluate" (Rossouw 412), fostering critical thinking abilities. Different and unexpected facets of an issue emerge when it is discussed by individuals from different backgrounds, allowing for the acquisition of a more complete intellectual picture. On the other hand, affective or "behavioral" competencies involve sensitivity and moral obligation. As insights emerge from exposure to the experiences of others, preconceived ideas and unexamined assumptions surface, leading students to become affectively engaged.

Evidence of teaching effectiveness was gathered at the conclusion of the course, including scores on formal course evaluations and students' written responses to questions designed by the instructor, meant to assess their reactions to course pedagogy and design. The class was composed of seventeen master of business administration (MBA) students, eight (47 percent) women and nine (53 percent) men, with ages ranging from 24 to 47 years $(M=30.76, S D=6.65)$. The students' years of full-time work experience ranged from three to twenty three years $(M=8.12, S D=5.60)$, and years of full-time college education ranged from three to seven years $(M=5.29$, $S D=1.11$ ). Formal course rating ranged from 6.44 to 6.94 on a scale of a 1 (low) to 7 (high) on items including overall course quality, organization of materials, instructor effectiveness, importance of knowledge gained, students' freedom to ask questions and express opinions, and appropriateness of the instructor's encouragement of student discussion.

The recommendations presented in the following sections include, among others, setting the physical stage for conversational learning, using the grading system appropriately, and addressing the unpredictable nature of conversations. They are meant to encourage teachers across subjects, particularly novice teachers, to experiment with discussion of controversial problems in their own classrooms. Excerpts from the students' written comments are presented following some of the formulated recommendations, as evidence backing the appropriateness of these suggestions.

\section{Set the Physical Stage for Conversational Learning}

The physical setting, such as classroom setting and class size, will influence the success of any conversational learning effort (Sims 2002). In my course, for example, we were assigned a traditional classroom; however, the students and I rearranged the seating into a U-shaped form so we were all able to see each other. I believe that this facilitated a sense of equality and community early in the semester, one that invited the kind of trust necessary for conversational learning. When the term ended, we collectively placed the seating back to its original organization, humorously remarking how fast time had gone by, and unknowingly engaging in a hands-on debriefing experience.

Class size also affects conversational learning, although this might not be within the instructor's sphere of influence. Evidence on the relationship between class size and student learning remains mixed (Borland, Howsen, and Trawick 2005), with evidence that teaching quality generally matters more (Pedder 2006). Should instructors be faced with a large class, they will need to consider whether conversational learning is appropriate. Breaking down the class into smaller discussion groups might be helpful in this case. The effect of class size on class participation was indeed noticed by a student in her written comment:

I think you should not let the course get much larger. I don't think that people are as comfortable talking and sharing their opinions when the class gets too large and they sometimes don't feel like they need to talk or can talk.

In contrast, classes that are too small can be stressful to students who might feel the "burden" of having to consistently participate. Here, I suggest that students take turns leading discussions. Educators might also consider including teaching tools that momentarily "relieve" students from conversing, such as guest speakers or movies relevant to the topic. All in all, the physical environment is critical to the conversational learning effort.

\section{Recognize and Strive to Overcome Initial Student Resistance}

Teachers might find that not all students will initially share their enthusiasm for conversational learning. With a college education becoming prohibitively expensive, students might resist conversations' lack of immediate practical utility, hoping to acquire rapidly marketable skills instead (A. Y. Kolb et al. 2002). Moreover, conversational learning challenges the hierarchy of educational institutions, where students are generally considered subordinate to faculty. Students, particularly women, might fear appearing unintelligent to their teachers as well as to their peers (Wasburn 2004). Last, instructors must acknowledge that most teaching still occurs through lectures and that few classroom experiences are entirely structured around conversations, which also predisposes students to resist them. According to Innes (2007):

[O]ur students come to the university with many years of training in listening passively and answering brief questions from the teacher with correct answers. Teachers rarely ask students how they arrived at their answers ... School has not been a place where students and teachers come together to talk about important questions. School has been a place where students try to guess what the teacher wants them to say. (13)

Several students noted their resistance to class conversations in their written comments, whether resulting from a lack of confidence or fear of appearing unintelligent to their teacher and classmates:

Overall, the course is very interesting and very conducive not only to learning through discussion but also to testing concepts, comparing experiences and in general, gaining confidence in expressing and defending viewpoints.

I am not sure why I have been so nervous about publicly speaking since I am about midway through the completion of the MBA, but all I have to do is hear my voice be the lone one vocal and I get to the point where I feel it would probably be better to hide underneath the desk or run out of the room. There is just something about being surrounded by knowledgeable people that kind of makes me feel like a fraud when I try to say something academic.

Fortunately, however, instructors can also count on the fact that many students, in particular experienced, upper-level students, will welcome classes that provide opportunities for discussion, as noted in two other student comments:

I chose to take this course because of my interest in improving my managerial skills. 
I also chose this course because I've taken the BUS 590 Colloquium courses in the past and have enjoyed the discussion type format and interactive learning.

I would have to say that it was one of the best courses I've taken in my time at [name of university]. The variety of topics that we covered kept each class interesting. The structure of the course also kept things moving along and helped prevent boredom. The focus on discussion more than lecturing was also important in my favorable impression of the course.

To overcome any initial opposition, I suggest that educators ask their students on the first day of class to consider the role of conversations in their lives. How often do we engage in conversations with others, and why? What is the role of conversation in organizations? Through this initial discussion, students will conclude that conversations are fundamental to the human experience and that we learn a great deal by talking and listening to others. Throughout the semester, teachers should model their behavior so that students understand that challenging others, including the instructor, is acceptable and central to their learning (Currie and Knights 2003; Gratton and Ghoshal 2002). In this process, educators need to balance carefully their roles as teachers and conversational participants, a concern that I address later in this article.

\section{Use the Grading System to Support Discussion}

The class reward system-explained verbally and detailed in the syllabusmust be designed to support discussion. Students must understand that their success in the course is contingent on participation (Henning 2005). At the same time, however, educators must strike a balance between motivating conversation through the grading system and encouraging students to enjoy it intrinsically and willingly engage in it. Moreover, the grading system must not punish those who, for cultural or personal reasons, do not wish to participate or do so only on occasion (Keith-Spiegel et al. 2002).

In my course, students earned grades on presentation and discussion of a news brief ( 5 percent), class participation (15 percent), two take-home examinations (assigned to encourage prior preparation of readings and each accounting for 20 percent), and a research paper and presentation (40 percent). Students' class attendance, punctuality, prior preparation of reading materials, readiness to engage in class discussion, attentiveness to and empathy toward the views of others, as well as overall quantity and quality of engagement in class conversations were used to evaluate class participation.

When asked about the appropriateness of the grading system in supporting discussion, students' reactions were generally favorable to the standards and criteria used to encourage discussion and evaluate class performance:

If a student knows that participation is weighted heavily, he or she is more inclined to participate and become familiar with the reading material to participate in discussions.

I think a midterm and final should be required for this course. It is an excellent gauge of how well the students understand the material covered in class and in the articles. The take home essay test requires students to think "outside of the box" in order to formulate an answer to a question. In addition, the essay exam is a good format because it allows for more time to cover new material during class.

I think that both the midterm and the final need to be retained in the course. Both were time consuming but necessary. In completing the midterm, I found myself reviewing the reading materials over and over again. I don't think the same kind of "ownership" of the concepts covered would be gained without the take home exams.

\section{Recognize Student Differences}

Few social interactions provide as much evidence of individual differences as conversations do. Teachers will observe different patterns of participation among students, such that some "talk a lot" while others are more reserved. In general, older and "nontraditional" students participate more willingly, partly because they have more experience and feel less of a power distance from their teachers (Weaver and Qi 2005). This is why courses grounded on the pedagogy of conversational learning will probably be more suitable to upper-division and graduate students, and teachers should be careful to choose topics appropriate to their student demographics. On the other hand, evidence of a connection between gender and participation is mixed, but we do know that teachers play a central role in encouraging the class participation of women (Salter and Persaud 2003). In her insightful article on creating woman-friendly classrooms, Wasburn (2004) suggests raising awareness of the influence of gender on class dynamics and emphasizing differences among women.

In essence, teachers must learn to capitalize on student differences rather than viewing them as a hindrance. One student in my class noted the benefit provided by our diverse classroom:

There was a good variety of backgrounds, age levels, and areas of employment that lends itself to interesting dialogue. The course structure, the module design with the pre-assigned readings and probing questions, was very effective. I found I had ample time to prepare for class and was ready to participate in the class discussions.

In the early days of the course, I advise educators to enthusiastically welcome those students who readily answer questions and debate viewpoints to start conversations. When noticeably praised by the teacher, these students model the behavior to others and incite them to engage. At the same time, instructors must be careful that the active students do not garner excessive attention, dominate conversations, or discourage others from participating. Should that occur, the instructor might need to remind them of his or her expectations of courtesy and mutual respect while acknowledging and praising their enthusiasm. Teachers should also stress the importance of everyone's contribution. They should not hesitate to call on the less talkative students and explore their reluctance to participate in private (Keith-Spiegel et al. 2002).

\section{Adopt a Modularized Approach to Course Organization}

In my course, I adopted a modularized approach to course structure, built around freestanding, autonomous, controversial topics. In other words, each class session's readings, discussions, and student presentations revolved around one specific domain. This structure differs considerably from the linear progression typical of traditional courses; however, it can provide educators with many avenues for flexibility and creativity in their teaching. For example, modules can be added or removed without affecting overall course 
structure. Topics of particular interest to teachers and their students can be incorporated into the course as well as modules focused on emerging issues, in an updateas-you-go format. The modular design also allows for inclusion of materials from other disciplines and the use of various pedagogical tools such as guest speakers, films, and literary narratives, all of which can greatly enrich and enliven classroom discussions. Several students in my class were particularly attracted to this modularized course organization:
State of Labor Unions; Women in the Workplace; Work-Life Balance Today; and Appearance, Attire, and Attractiveness. In general, topics must be focused enough to allow for in-depth analysis and controversial enough to stimulate thinking, feeling, and a desire to engage. The students' written responses indicated a clear interest in the chosen topics:

The class encouraged discussion and participation and the topics were easy to relate to and were often controversial to generate discussion. The information was not all cut

CONVERSATIONS CANNOT TRANSLATE INTO LEARNING WITHOUT MEMBERS HAVING SOME PRIOR EXPOSURE TO AND FAMILLARITY WITH THE TOPIC. SUCCESSFUL CONVERSATIONS MUST THEREFORE INVOLVE TOPICS THAT ARE "REAL" TO THE PARTIES. THE TOPICS I CHOSE WERE FOCUSED ON MANAGERIAL PROBLEMS TO WHICH STUDENTS COULD RELATE.

I would rate this course as among the best I have experienced in the 5 years that I've been in the program. I thought the topics were appropriate and interesting. I liked the structure of the course and the discussion-type format. I tend to learn and retain a lot more when courses are structured like this one.

I really liked the layout and organization of the course. I have never been in a discussion class set up like this course and as such, I've never been in one that progressed as well as this course did. I found myself really enjoying going to class.

\section{Choose Relevant, Interesting Conversational Topics}

Conversations cannot translate into learning without members having some prior exposure to and familiarity with the topic. Successful conversations must therefore involve topics that are "real" to the parties (Henning 2005). The topics I chose were focused on managerial problems to which students could relate. These were organized into seven modules and two workshops. The modules included Corporate Ethics and Corruption; Technology, Creativity, and Innovation; Downsizing and Its Consequences; Occupational Patterns and Trends; The ally, the workshops provided a breather from the pace of our class discussions. The students were appreciative of the learning and coaching opportunities provided by these workshops:

The workshops you set up were fantastic; thank you for caring enough to do that. I realize that many in my class are very happy in their positions and have had wonderful work experiences; however, there are those such as myself that are in the MBA program to move into another area of business and, hopefully, to a different company.

The cross-cultural workshop was extremely beneficial. I especially liked the interactive nature of the workshop. I also found it extremely enlightening to learn some of the core values and forces that shape the different cultures that we reviewed.

I really liked the workshop idea. Many times MBA students are commuters and have a hard time getting to any activities within the college outside of class. I have wanted to go to one of the workshops the career center holds, but have never been able to attend due to the scheduling.

Last, educators should expect that not all topics will be equally appealing. At the beginning of the semester, teachers can ask students to select the topics they find most intriguing to guarantee their interest and maximize the likelihood of their participation. This also allows students to actively direct their learning.

\section{Adopt Current and Accessible Reading Materials}

Students must familiarize themselves with the topic through reading because prior preparation boosts students' confidence and fosters a greater desire to participate (Weaver and Qi 2005). In this course, students had early access to course materials through binders available at the bookstore. The materials used included academic-practitioner readings, news briefs, and student projects.

First, students were required to read articles from "pracademic" publications such as Harvard Business Review and to reflect on broad study questions assigned for each article. For example, the Parable of the Sadhu (McCoy 1997), assigned for the module on Corporate Ethics and Corruption, was meant to provide a real ethical dilemma that students could debate. Such journals generally convey academic 
findings in language accessible to students. Second, students and the instructor took turns presenting news briefs, essentially inspecting publications such as The Wall Street Journal and Business Week for relevant stories. Current affairs constitute useful teaching materials because they portray events pertinent to what managers face daily, add energy to the classroom, and foster in students the habit of remaining current (Phillips and Clawson 1998). Last, students investigated specific topics related to one of the modules and shared a report and presentation with their classmates. This encouraged the students to generate and share knowledge with others and to lead ensuing class discussions. This blurring of teacher-student roles is fundamental to successful conversational learning (Sims 2004). The students' reactions to these course materials were generally favorable, as suggested by the following excerpts:

The course was extremely interesting and educational. I particularly liked the form of the text-a collection of current articles. I really prefer this to an outdated textbook.

Most of my IS [information systems] classes consist of a professor lecturing for an entire 2.5 hours. The format of this class was much more stimulating. . . The news brief was an excellent idea because it gave students the opportunity to be more independent and creative in selecting articles for discussion.

The reading of the articles and then class discussion of them was a great way to understand about the issues. There are many people that have been involved with each of these issues in their current or past jobs, so hearing about the issues as they relate to people in the room was enlightening.

I also enjoyed the readings and discussion, followed-up with student presentations, which I thought did an excellent job of rounding out the material.

\section{Find Creative and Provocative Ways of Launching Conversations}

Conversations always need a starting point. In my course, the students generally started the conversations because they took turns starting class with the news briefs. Other ways recorded in research include the Socratic Method, meaning the process of discovering through successive questioning (Baker, Jensen, and Kolb 2002a). Instructors start with broad and simple questions, leading students toward basic understanding through questioning, and then integrating logic, reasoning, and argumentation into the conversation. Here, educators need to be provocative without being threatening.

Additionally, initial discussions of basic and "objective" facts can put individuals at ease and prepare them for the more tense conversations around their feelings on these facts. Therefore, instructors can begin conversations with an overview of the content of the readings before shifting to the students' emotional reactions. The latter type of conversation develops the affective competencies mentioned earlier in this article (Gratton and Ghoshal 2002).

\section{Recognize that Successful Conversations Can Be Unpredictable and Emotionally Charged Experiences}

Conversations about controversial issues can follow unpredictable paths and come across points where emotional awareness is heightened and strong feelings are stimulated. Instructors must realize that they have achieved success leading the discussion when students engage with each other with minimal encouragement, and debate on an affective rather than merely intellectual level. In my course, I felt that the students were extremely comfortable because they often shared stories of unfortunate events surrounding job loss, betrayal in personal and professional relationships, and uncertain careers. A few weeks into the semester, minimal stimulation was required on my part to sustain discussion.

Nevertheless, this comfort level can lead conversations to veer off course occasionally. When this happens, the challenge for the teacher is no longer to encourage discussion but to artfully guide it toward "teachable moments" (Henning 2005). Because conversational learning is more about process than an end goal, educators need to remain positive and supportive when students make off-target remarks, and they should simply redirect the conversation (Sims 2004).

Moreover, when discussing controversies in any field, instructors must ensure that all sides are addressed so that students can disagree without fear of derision (Keith-Spiegel et al. 2002). The session on Women in the Workplace was particularly interesting in that respect because the male and female students held clearly different opinions in regards to why so few women make it to the top organizational rungs and why the wage gap exists despite decades of legislation. However, I sensed that we had reached that level of psychological safety critical to conversational learning because the students seemed relaxed, attentive, and comfortable debating their opinions and sharing personal experiences, without any visible signs of offense, and despite the sensitivity of the subject matter. The students' written comments provided additional support for my own subjective sense that the class was psychologically conducive to open discussions:

It was nice to have a class that provided a relaxing atmosphere that encouraged discussions. Too many classes are structured in a way that does not allow class participation or discussion. . . . The professor has a lot of knowledge to give to the students and the students in return also have a lot of experience and knowledge to bring into the classroom. Together this provides a very exciting learning atmosphere which is the type of atmosphere I learn best in.

I really loved the course. I enjoyed the "grayness" of the subject matter. Opinions that I had and thought were unquestionable-like outsourcing being wrong-were shaken and turned. ... An excellent surprise for me was the student involvement in the discussions. In previous classes, I've been amazed at the lack of involvement from my peers, but in this class, most everyone seemed to be genuinely interested and willing to provide feedback. Discussion consistently crossed over into the nightly break, as well as outside in the parking lot. [One student] and I talked for nearly an hour after class about work-life balance. I think that this alone is a testament to the subject matter, structure, and facilitator.

This was a great course. The discussions on current real-world work topics was valuable and the atmosphere of the course allowed everyone to give their opinion and input. Most classes discuss case studies that are sometimes elaborated real world experience or created to attempt to prove an existing management theory which sometimes does not fit into the typical business environment. Also, the class "culture" encouraged input from all students which is unusual; generally, a quarter of a class will discuss most topics and there will be a quarter of the class that you will never hear from. The relaxed atmosphere and open forum for discussion was the perfect learning environment for these topics. 
Last, emotionally charged conversations might provoke students to make prejudicial statements toward an issue. Teachers need to quickly consider whether the remark has any redeeming qualities. If so, they must turn the statement into a learning opportunity by asking students to comment on it and call into question the underlying assumptions. When judiciously applied to learning, humor can be a powerful tool to relax the atmosphere (Garner 2006). If no such opportunity is possible, the comment must be handled swiftly with an observation that biased statements simply do not belong in institutions of higher learning.

\section{Carefully Balance the Roles of Teacher and Conversational Participant}

Effective classroom discussions necessitate a fundamental change in the instructor-student dynamic from hierarchy to conviviality and mutual receptivity (Howard 2002). This change is anxiety-provoking for teachers because it implies loss of control over the classroom (Baker, Jensen, and Kolb 2002a). To complicate matters further, students can often sense teachers' discomfort, which can weaken teacher credibility (Sims 2004). Especially at risk are junior faculty who need to demonstrate teaching competence to promotion and tenure committees and educators whose disciplines do not easily lend themselves to discussion.

Because research suggests that students are less likely to participate when they view faculty as experts (Weaver and Qi 2005), I stressed my role as a conversational facilitator as opposed to expert on the first day of class, confessed to my lack of expertise in most topics, and expressed my eagerness to learn from the class. In seeking to build trust, I sometimes shared my own experiences, while being careful not to disclose intimate revelations that do not relate to classroom learning. Further, I tried to avoid lecturing and assuming a position of "enlightened superiority" (Currie and Knights 2003, 40), although I confess to occasional temptations. The students' own experiences needed to be given priority throughout. I also endeavored to interact with students by chatting with them during breaks or after class. One recent study showed that faculty-student interac- tion generated the largest effect on student participation (Weaver and Qi 2005). In doing so, educators must also be mindful of the ethical issues that can emerge when students and teachers interact on a personal level (Keith-Spiegel et al. 2002). Earlier in this article, I also mentioned the importance of redirecting the conversation as need be, carefully handling prejudicial statements, and managing various participation levels, all of which are also central to this balancing act.

Discussion is probably one of the most powerful pedagogical tools available to teachers (despite being anxiety-provoking to both them and their students) because it exposes students to a variety of viewpoints and allows them to relate to others, fostering the cognitive and affective competencies mentioned earlier. Indeed, the students' comments provided evidence of learning such competencies:

The most interesting part of the readings was finding something out about the topic that I did not realize that I was doing or information in areas I was not aware of. For example, the article "How unethical are you?" really pointed out some ways I am biased that I would have never realized existed. I realized that after reading that I may approach things differently and really try to be aware of actions I take that I didn't even think were unethical actions.

I really believe I grew as a manager as a result of this course. As I reflect on this past semester and try to differentiate between class and work, I'm realizing that the lines have become blurred. Ultimately, this is a good thing. My experiences gained while implementing a care coordination model at the Medical Center, piloting a new patient care delivery model on my unit as well as the roll out of a clinical information system have allowed me to use knowledge I've gained in class and integrate it into my work. I've also had the opportunity to share information with my boss about things I learned from class. I appreciated the freedom to do self-paced learning as well as gaining a wealth of knowledge through the presentations and papers.

How teachers can go about creating the right environment to aid in the development of such cognitive and affective competencies has not been sufficiently examined in the literature. I present several recommendations for creating a discussion-based course and facilitating a classroom environment conducive to discussion-generated learning. It is my hope that these recommendations, and the many avenues for flexibility and creativity provided by the course design that I shared here, will encourage teachers across disciplines to experiment with conversations of current and controversial issues as a means of teaching and learning.

\section{REFERENCES}

Baker, A. C., P. J. Jensen, and D. A. Kolb, eds. 2002a. Conversational learning: An experiential approach to knowledge creation. Westport, CT: Quorum.

Baker, A. C., P. J. Jensen, and D. A. Kolb. 2002b. Learning and conversation. In Baker, Jensen, and Kolb 2002a, 1-13.

Billings, L., and J. Fitzgerald. 2002. Dialogic discussion and the Paideia seminar. American Educational Research Journal 39 (4): $907-41$.

Borland, M. V., R. M. Howsen, and M. W. Trawick. 2005. An investigation of the effect of class size on student academic achievement. Education Economics 13 (1): 73-83.

Brookfield, S. D., and S. Preskill. 1999. Discussion as a way of teaching: Tools and techniques for university teachers. Buckingham, UK: Society for Research into Higher Education and Open University Press.

Currie, G., and D. Knights. 2003. Reflecting on a critical pedagogy in MBA education. Management Learning 34 (1): 27-49.

Garner, R. L. 2006. Humor in pedagogy: How ha-ha can lead to aha! College Teaching 54 (1): $177-80$.

Gratton, L., and S. Ghoshal. 2002. Improving the quality of conversations. Organizational Dynamics 31 (3): 209-23.

Henning, J. E. 2005. Leading discussions: Opening up the conversation. College Teaching 53 (3): 90-94.

Howard, L. A. 2002. From ivory tower to town hall: Using dialogical inquiry as a critical pedagogy. American Behavioral Scientist 45 (7): 1125-34.

Innes, R. B. 2007. Dialogic communication in collaborative problem solving groups. International Journal for the Scholarship of Teaching and Learning 1 (1): 1-18.

Keith-Spiegel, P., B. E. Whitley Jr., D. Ware Balogh, D. V. Perkins, and A. F. Wittig. 2002. The ethics of teaching: A casebook. 2nd ed. Mahwah, NJ: Erlbaum.

Kolb, A. Y., A. C. Baker, P. J. Jensen, and D. C. Kayes. 2002. The practice of conversational learning in higher education. In Baker, Jensen, and Kolb 2002a, 207-21.

Kolb, D. A., A. C. Baker, and P. J. Jensen. 2002. Conversation as experiential learning. In Baker, Jensen, and Kolb 2002a, 51-66.

McCoy, B. H. 1997. The parable of the Sadhu. Harvard Business Review 75 (3): 54-64.

Pedder, D. 2006. Are small classes better? Understanding relationships between class size, classroom processes, and pupils' learning. Oxford Review of Education 32 (2): 213-34. 
Phillips, R. A., and J. G. Clawson. 1998. Current events periodicals and business ethics. Teaching Business Ethics 2 (2): 165-74.

Rossouw, G. J. 2002. Three approaches to teaching business ethics. Teaching Business Ethics 6 (4): 411-33.

Rynes, S. L., and C. Q. Trank. 1999. Behavioral science in the business school curriculum: Teaching in a changing institutional environment. Academy of Management Review 24 (4): 808-24.

Salter, D. W., and A. Persaud. 2003. Women's views of the factors that encourage and discourage classroom participation. Jour- nal of College Student Development 44 (6): $831-44$.

Sims, R. R. 2002. Teaching business ethics for effective learning. Westport, CT: Quorum. 2004. Business ethics teaching: Using conversational learning to build an effective classroom environment. Journal of Business Ethics 49 (2): 201-11.

Wasburn, M. H. 2004. Is your classroom womanfriendly? College Teaching 52 (4): 156-58.

Weaver, R. R., and J. Qi. 2005. Classroom organization and participation: College students' perceptions. Journal of Higher Education 76 (5): 570-601.

\section{RECOMMENDED READING}

Bohm, D. 1996. On dialogue. London: Routledge. Dewey, J. 1916. Democracy and education. New York: Free Press.

Freire, P. 1998. Pedagogy of freedom: Ethics, democracy, and civic courage. Trans. P. Clarke. Lanham, MD: Rowman and Littlefield.

Isaacs, W. 1999. Dialogue and the art of thinking together. New York: Currency-Doubleday.

Tannen, D. 2005. Conversational style: Analyzing talk among friends. New York: Oxford University Press.

Zeldin, T. 1998. Conversation: How talk can change your life. London: Harvill Press. 